Open Access

\title{
Numerical Investigation of Seismic Behavior of Spatial Asymmetric Multi- Storey Reinforced Concrete Buildings with Masonry Infill Walls
}

\author{
Triantafyllos Makarios*, ${ }^{1}$ and Panagiotis G. Asteris ${ }^{2}$
}

\author{
${ }^{1}$ Institute of Engineering Seismology \& Earthquake Engineering (ITSAK), 5 Ag. Georgiou Str, Patriarchika, 555 35, \\ Pylaia, Thessaloniki, Greece; ${ }^{2}$ Computational Mechanics Laboratory, School of Pedagogical \& Technological Educa- \\ tion, 14124 Heraklion, Athens, Greece
}

\begin{abstract}
In order to insure the validity of the seismic performance matrix of the Eurocode EN 1998 for irregular in-plan, torsionally-flexible, spatial, asymmetric, multi-storey reinforced concrete (r/c) buildings with masonry infill walls, an extended parametric numerical investigation has been performed, using non-linear response-history analysis. For this purpose, $N$ representative asymmetric $\mathrm{r} / \mathrm{c}$ buildings with torsional sensitivity, have been designed according to Eurocodes EN 1990, EN 1992 and EN 1998-1, for Ductility Class High (DCH), using design global behavior factor $q$ equal to 3.00. Each of the masonry infill walls has been modeled with two nonlinear diagonal bars with hinges at their two ends and with onesided behavior (in compression only). Three seismic levels of the seismic action have been considered with mean return period of 2475, 475 and 275 years, respectively. The above three earthquakes have been used for validity check of the states of "Near Collapse", "Significant Damage" and "Damage Limitation", respectively. In order to apply the non-linear response-history analysis, suitable artificial accelerograms, which are compatible with the elastic response spectrum, for soil category D, of Eurocode EN 1998-1 on the one hand and with Hellenic geological and site-specific data on the other hand, have been used. In the present paper, important guidance on modelling plastic hinges and the masonry infill walls is presented, as well as, a numerical example of a three-storey $\mathrm{r} / \mathrm{c}$ building is also presented for illustrative purposes
\end{abstract}

Keywords: Inelastic static seismic analysis, non-linear response-history analysis, asymmetric multi-storey building, torsionally-flexible multi-storey building, masonry infill walls, simulation of plastic hinge properties.

\section{INTRODUCTION}

The present paper deals with the numerical investigation of the seismic behavior of irregular in-plan multi-storey reinforced concrete $(\mathrm{r} / \mathrm{c})$ buildings with masonry infill walls. These buildings have been designed according to Eurocodes EN 1992 [1] and EN 1998-1 [2], whilst afterwards their seismic capacity has been evaluated for various levels of earthquake excitations and respective seismic performance levels, according to the seismic performance matrix of Eurocode EN 1998-3 [3]. Non-linear response-history analysis has been applied. However, based on previous experiences with such analyses, the results may be deemed unreliable due to the following reasons:

a. Use of unsuitable accelerograms. Inadequate number of recorded accelerograms due to scars, limited seismic data at the site or due to frequency content of recorded ground motion, inadequate as regards the number of strong cycles of the dynamic loading as well as the strong motion duration or the Arias Intensity [4].

b. Use of false assumptions in the numerical models about the nonlinear dynamic properties of plastic hinges and

*Address correspondence to this author at the Institute of Engineering Seismology \& Earthquake Engineering (ITSAK), 5 Ag. Georgiou Str, Patriarchika, 555 35, Pylaia, Thessaloniki, Greece; Tel: (+)302310476081;

Fax: (+)302310476085; E-mail: makarios@itsak.gr
Moments-Chord Rotations $(M-\theta)$ diagrams. In other words, inaccurate simplifications or inappropriate assumptions of the nonlinear model adopted to describe the inelastic behavior of the structure.

c. Inadequacy of the numerical integration schemes, regarding accuracy \& stability;

d. Improper orientation of the pair of horizontal seismic components. In other words, the critical dynamic loading orientation of the pair of horizontal seismic components is unknown or does not exist and leads to the examination of various other orientations (at least one more orientation with 45 degrees rotation relative to the initial principal axes must be examined).

e. Omitting the vertical ground motion component or ignoring the P-Delta effects in the analysis.

In addition, in order to apply the inelastic static seismic analysis (pushover analysis) on irregular in-plan, asymmetric, torsionally-flexible multi-stotey $\mathrm{r} / \mathrm{c}$ buildings, one has to use suitable spatial model according to sect.4.3.3.4.2.1(2)P of Eurocode EN 1998-1 \& sect.4.4.4.1(2)P of Eurocode EN 1998-3. However, no additional details are given about the spatial model of the structure to be used in conjunction with the pushover procedure described in EN 1998. A realistic, mathematical methodology concerning the application of the static pushover method on irregular in-plan multi-storey buildings has been presented recently using an optimum 
equivalent non-linear single degree of freedom system, where the floor rotations around vertical axes are taken fully into account in combination with the equivalent static eccentricities and design inelastic spectra [5-7]. However, the simulation of inelastic properties of plastic hinges, as well as the Moment-Chord Rotation ( $M-\theta$ ) diagram of a structural member is a great issue that requires clarifications, and it is independent from the methodology of analysis that will be used. From the many available simulation techniques/methods (Monte Carlo method, importance sampling technique, response surface method etc) as well as others techniques that were presented in the past [8], here we apply the proposal of Eurocode EN 1998-3 in combination with the newly Hellenic Code of Retrofitting of $\mathrm{r} / \mathrm{c}$ buildings (KANEPE 2012) [9].

In the present article, all the necessary information for the simulation of plastic hinges of $\mathrm{r} / \mathrm{c}$ members, as well as that for the simulation of masonry infill walls is given in detail. The seismic performance of new $\mathrm{r} / \mathrm{c}$ buildings, which have been designed according to Eurocodes EN 1992 \& EN $1998-1$, is determined for various levels of the seismic performance matrix. The role of masonry infill walls of irregular in-plan multi-storey $\mathrm{r} / \mathrm{c}$ buildings is investigated. A suitable numerical example of a torsionally-flexible, irregular inplan, three-storey $\mathrm{r} / \mathrm{c}$ building is presented for illustrative purposes. It is worth noting that, for the needs of the nonlinear response-history analysis used in the present paper, new artificial accelerograms have been developed in the frame of the present article that are compatible with the Design Basis Earthquake (DBE) of Eurocode EN 1998-1 for soil category $D$.

\section{SIMULATION OF INELASTIC CHARACTERISTICS OF BUILDING}

\section{General}

In order to build a model of an $\mathrm{r} / \mathrm{c}$ building, each member (column or beam) can be assumed that it has deformed antisymmetrically (Fig. 1a), while the structural wall can develop plastic hinge at its base section only. Thus, each deformed member may be considered to consists of two "cantilevers", each having a length $L_{\mathrm{S}}$, which is called "shear length". According to sect.7.2.3 of KANEPE 2012 [9], it can be considered (approximately) that the shear length $L_{\mathrm{S}}$ is equal to one-half of the clear length of the structural elements. However, in the case of ductile r/c walls, with shear ratio $a_{\mathrm{s}}=M /\left(h \cdot Q_{\mathrm{y}}\right)>2.50$, where $h$ is the depth of the section into the moment plane, then the shear length $L_{\mathrm{S}}$ is equal to the distance from the base of wall until the zeromoment point due to a temporary lateral static loading of the building.

At the end-section of the base of each "cantilever", a suitable non-linear spring is set in the model of the building, which follows a particular non-linear law of Moment-Chord Rotation $(M-\theta)$. In order to obtain the diagram $M-\theta$, first, an elastic-plastic diagram of Moment-Curvature
( $M-\varphi$ ) has to be calculated for the base critical $\mathrm{r} / \mathrm{c}$ section of each cantilever. This can be achieved reliably by modelling the final designed $\mathrm{r} / \mathrm{c}$ section by "fiber elements" (i.e. software XTRACT/2007 [10]) using mean values of material strengths (i.e. $f_{\mathrm{cm}}=f_{\mathrm{ck}}+8$ in $\mathrm{MPa}$ for concrete and $f_{\mathrm{ym}}=1.10 f_{\mathrm{yk}}$ for steel) instead of their characteristic values $f_{\mathrm{ck}} \& f_{\mathrm{yk}}$. According to this methodology, the critical $\mathrm{r} / \mathrm{c}$ section is divided into the field of the confined concrete (which extends up to the loop of the axis of the external stirrup), in the field of unconfined concrete (which is outside of the loop of the axis of the external stirrup) and into longitudinal steel bars of the section (Fig. 2). For each one of the three fields mentioned above, a different appropriate stressstrain diagram $(\sigma-\varepsilon)$ is used. Such suitable diagrams $\sigma-\varepsilon$ are given at Figs. (3-5).
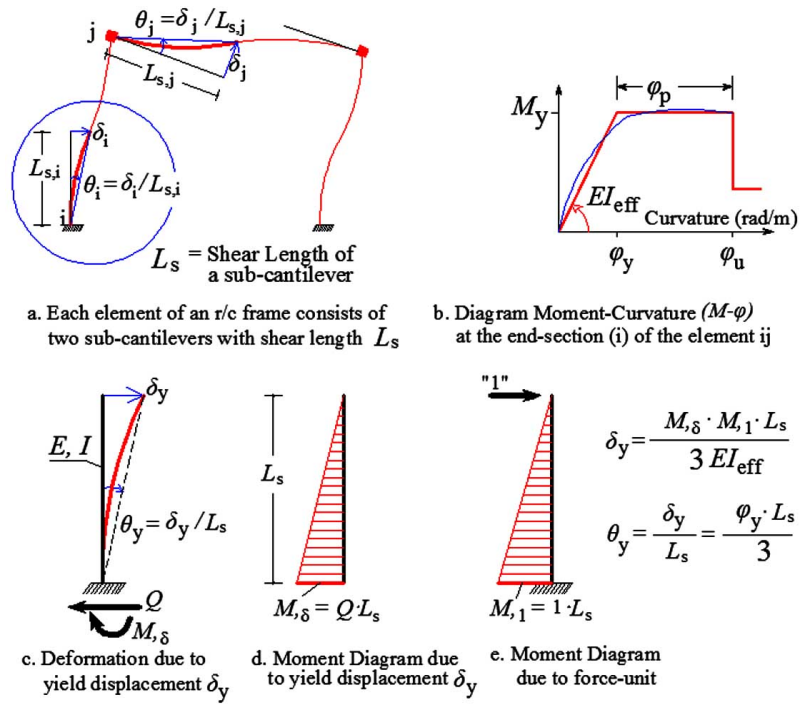

Fig. (1). Definition of chord rotation of a cantilever.
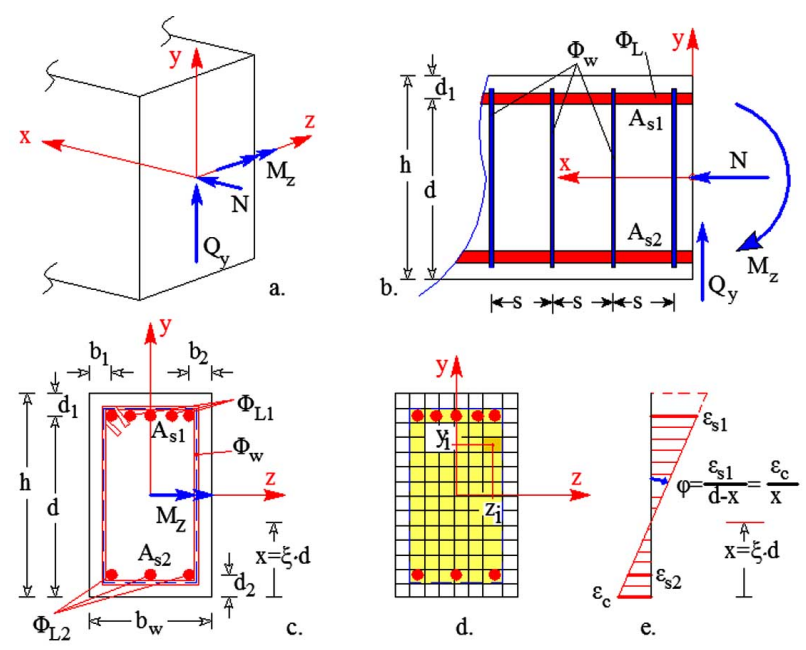

Fig. (2). Section analysis using fiber elements. 


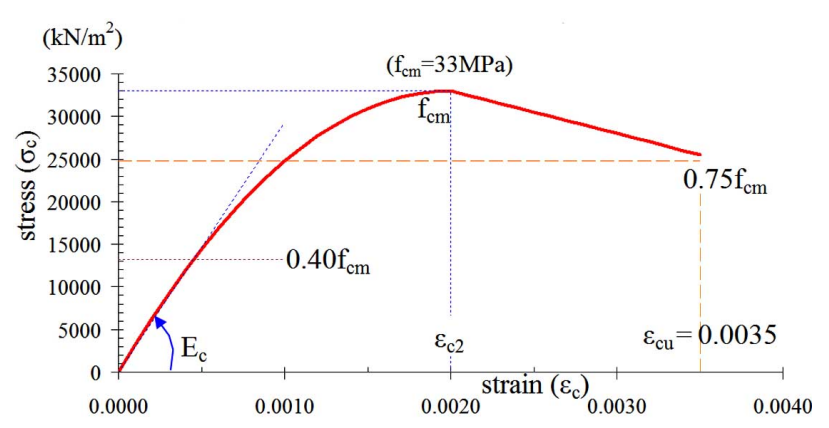

Fig. (3). Stress-strain $(\sigma-\varepsilon)$ diagram for unconfined concrete section, category $\mathrm{C} 25 / 30$ using mean strength.

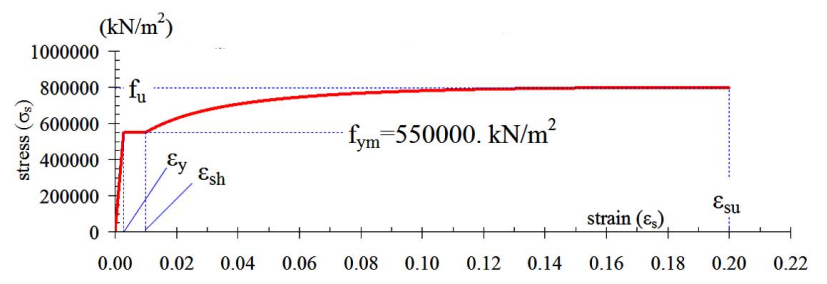

Fig. (4). Stress-strain $(\sigma-\varepsilon)$ diagram for steel, category B500c using mean strength.

The stress-strain diagram $\sigma-\varepsilon$ of confined coreconcrete can be calculated based on the "model of confined concrete" that is proposed by Eq.(A.6-A.8)/sect. A.3.2.2 of Eurocode EN 1998-3, Fig.(5). In that model, the strength $f_{\mathrm{cc}}$ of the confined concrete and its contemporary strain $\varepsilon_{\mathrm{cc}}$ is given as follows:

$$
\begin{aligned}
& f_{\mathrm{cc}}=f_{\mathrm{cm}}\left[1+3.7 \cdot\left(\frac{a \cdot \rho_{\mathrm{sy}} \cdot f_{\mathrm{yw}, \mathrm{m}}}{f_{\mathrm{cm}}}\right)^{0.86}\right] \\
& \varepsilon_{\mathrm{cc}}=\varepsilon_{\mathrm{c} 2}\left[1+5 \cdot\left(\frac{f_{\mathrm{cc}}}{f_{\mathrm{cm}}}-1\right)\right]
\end{aligned}
$$

where $f_{\mathrm{cm}} \& \varepsilon_{\mathrm{c} 2}$ are the compressive strength (mean value) and corresponding strain of unconfined concrete, respectively (Fig. (3)).

The ultimate strain $\varepsilon_{\mathrm{cu}}$ of the extreme fiber of the pressure zone of the section is given:

$$
\varepsilon_{\mathrm{cu}}=0.004+0.5 \cdot \frac{\alpha \cdot \rho_{\mathrm{sy}} \cdot f_{\mathrm{yw}, \mathrm{m}}}{f_{\mathrm{cc}}}
$$

where $f_{\mathrm{yw}, \mathrm{m}}$ is the yielding stress (mean value) of the stirrups and $\alpha$ is the "confinement effectiveness factor" of the core that is given as:

$$
\alpha=\left(1-\frac{s_{\mathrm{h}}}{2 b_{\mathrm{c}}}\right) \cdot\left(1-\frac{s_{\mathrm{h}}}{2 h_{\mathrm{c}}}\right) \cdot\left(1-\frac{\sum b_{\mathrm{i}}^{2}}{6 \cdot b_{\mathrm{c}} \cdot h_{\mathrm{c}}}\right)
$$

where $b_{i}$ is the centerline spacing of longitudinal bars laterally restrained by a stirrup corner along the perimeter of the cross-section, so the buckling phenomenon of these steel bars is eliminated.

$h_{\mathrm{c}}$ and $b_{\mathrm{c}}$ is the dimension of confined core to the centerline of the hoop.

It should be noted that, in the case when the stirrups are not closed with hooks that have an angle of more than $45^{\circ}$, then concrete confinement must be ignored and for this reason the "confinement effectiveness factor" is set to zero $(\alpha=0)$.

$$
\rho_{\mathrm{sy}}=\frac{A_{\mathrm{sy}}}{b_{\mathrm{w}} \cdot s_{\mathrm{h}}} \text { is the ratio of transverse steel parallel to }
$$
the loading direction $y$ of the section (Fig. (2)), $A_{\text {sy }}$ is the total area of the stirrup sections along the loading direction $y$ and $s_{\mathrm{h}}$ is the pure stirrup spacing along the length $x$ of the structural member.

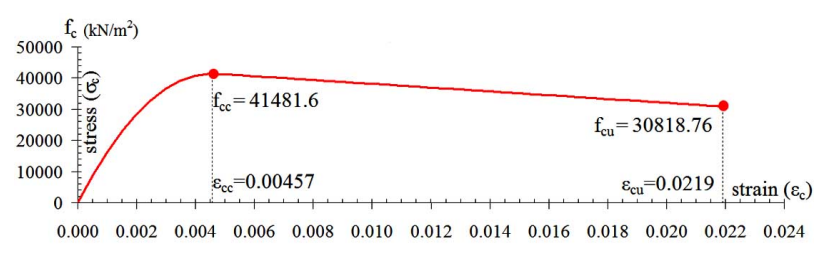

Fig. (5). Stress-strain $(\sigma-\varepsilon)$ diagram for confined concrete core (C25/30 \& B550c) according to EN 1998-3

\section{Calculation of the Chord Rotation $\grave{e}_{y}$ of a Cantilever for the "Damage Limitation" Limit State}

Following the calculation of the elastic-plastic diagram of Moment-Curvature $M-\varphi$ of the end critical section at the base of each cantilever, its chord rotation $\theta_{\mathrm{y}}$ for the "Damage Limitation" limit state can be calculated. For this purpose, the following two assumptions are made: (a) the behavior of the cantilever is linear-elastic until the appearance of the yield state at its base (Fig. 1b), and (b) the variation of the corresponding lateral yield displacement of the free-end of the cantilever, $\delta_{\mathrm{y}}$, is as shown in Fig. (1c). Next, at the base of the cantilever, the yielding curvature $\varphi_{\mathrm{y}}$ is calculated, while the chord rotation $\theta_{\mathrm{y}}$ of the cantilever is obtained elastically as $\theta_{\mathrm{y}}=\varphi_{\mathrm{y}} \cdot L_{\mathrm{S}} / 3$, (Fig. 1d,e). However, there are more sources that contribute in yield rotations of the end-section, such as the action of shear force and the extraction or lap-splice slip of longitudinal steel bars from the fixed-base (or the join) of the cantilever. For this reason, it is preferable to use Eq.(5) that is proposed by Eq.(A.10a)/sect.A.3.2.4 of Eurocode EN 1998-3, [11, 12]:

$\theta_{\mathrm{y}}=\frac{\varphi_{\mathrm{y}} \cdot\left(L_{\mathrm{S}}+a_{\mathrm{v}} \cdot z\right)}{3}+0.00135 \cdot\left(1+\frac{1.50 \cdot h}{L_{\mathrm{S}}}\right)+\frac{\varepsilon_{\mathrm{y}} \cdot d_{\mathrm{b}} \cdot f_{\mathrm{ym}}}{6 \cdot\left(d-d_{1}\right) \sqrt{f_{\mathrm{cm}}}}$

where $a_{\mathrm{v}}$ is zero when the flexural failure precedes the shear failure and $a_{\mathrm{v}}$ is one when the shear failure precedes the flexural one, $z$ is the length of internal lever arm, taken 
equal to $d-d_{2}$ in beams and columns, $d$ and $d_{2}$ being the depths to the tension and compression reinforcement for the external compressive fiber of the section, respectively. Also, $d_{1}$ is the distance from the tension reinforcement to external tension fiber of the section, $h$ is the depth of the geometric section of the member (Fig. 2), $\varepsilon_{\mathrm{y}}$ is the steel strain that is taken equal $\varepsilon_{\mathrm{y}}=f_{\mathrm{ym}} / E_{\mathrm{S}}, E_{\mathrm{S}}$ is the Elasticity Modulus of the steel and $f_{\mathrm{ym}} \& f_{\mathrm{cm}}$ are the yielding stress (mean value in $\mathrm{MPa}$ ) of steel \& concrete, respectively.

\section{Calculation of Chord Rotation $\boldsymbol{\theta}_{\mathrm{u}}$ of a Cantilever for the "Near Collapse" Limit State}

The chord rotation $\theta_{\mathrm{u}}$ of a cantilever, for the "Near Collapse" limit state under cyclic loading, can be calculated by Eq.(6) that is proposed by Eq.(A.1)/sect.A.3.2.2 of Eurocode EN 1998-3:

$\theta_{\mathrm{u}}=\frac{1}{\gamma_{\mathrm{el}}} \cdot 0.016 \cdot 0.3^{v} \cdot\left(\frac{p_{2}}{p_{1}} \cdot f_{\mathrm{cm}}\right)^{0.225} \cdot a_{\mathrm{s}}^{0.35} \cdot\left(25^{\alpha \cdot \rho_{\mathrm{sy}} \cdot \frac{f_{\mathrm{yw}, \mathrm{m}}}{f_{\mathrm{cm}}}}\right) \cdot\left(1.25^{100 \rho_{\mathrm{d}}}\right)$

where,

$\gamma_{\mathrm{el}}$ is a safety factor that is taken equal to 1.50 for primary seismic structural members (due to scattering of the experimental values) and 1.00 for secondary seismic members.

$p_{1}=\max (0.01, \omega)$ and $p_{2}=\max \left(0.01, \omega^{\prime}\right)$, with $\omega \&$ $\omega^{\prime}$ are the mechanical reinforcement ratios of the tension reinforcement $A_{\mathrm{s} 1}$ (with the intermediary reinforcement) and the compression one $A_{\mathrm{s} 2}$, respectively:

$$
\begin{gathered}
\omega=\rho_{1} \cdot \frac{f_{\mathrm{ym}}}{f_{\mathrm{cm}}}=\frac{A_{\mathrm{s} 1}}{b_{\mathrm{w}} \cdot d} \cdot \frac{f_{\mathrm{ym}}}{f_{\mathrm{cm}}}, \omega^{\prime}=\rho_{2} \cdot \frac{f_{\mathrm{ym}}}{f_{\mathrm{cm}}}=\frac{A_{\mathrm{s} 2}}{b_{\mathrm{w}} \cdot d} \cdot \frac{f_{\mathrm{ym}}}{f_{\mathrm{cm}}} \quad(7 \mathrm{a}, \mathrm{b}) \\
v=\frac{N}{b_{\mathrm{w}} \cdot h \cdot f_{\mathrm{cm}}} \text { is the normalized axial force }\left(b_{\mathrm{w}}\right. \text { is the }
\end{gathered}
$$

width of compression zone and force $N$ is taken positive for compression, Fig. 2)

$$
\rho_{\mathrm{d}}=\frac{A_{\mathrm{sd}}}{b_{\mathrm{w}} \cdot d} \text { is the steel ratio of diagonal reinforcement }
$$
$A_{\mathrm{sd}}$ (if it exists)

$$
a_{\mathrm{S}}=M /\left(h \cdot Q_{\mathrm{y}}\right)=L_{\mathrm{S}} / h \text { is the ratio moment } / \text { shear, }
$$

which is called shear ratio, at the end-section of the cantilever (Fig. 2)

$\alpha$ is the "confinement effectiveness factor" of the coreconcrete that is given by Eq.(4):

For the case of $\mathrm{r} / \mathrm{c}$ walls, the chord rotation at the limit state of "Near Collapse" given by Eq.(6) is divided by a factor 1.60. Moreover, the plastic rotation $\theta_{\mathrm{p}}$ is always given by $\theta_{\mathrm{p}}=\theta_{\mathrm{u}}-\theta_{\mathrm{y}}$, while the chord rotation of the cantilever at limit state of "Significant Damage" is taken equal to with the $0.75 \theta_{\mathrm{u}}$ according to sect.A.3.2.3 of Eurocode EN 1998-3.

\section{Calculation of Cyclic Shear Strength $V_{R}$ of a Cantilever}

The cyclic shear strength $V_{\mathrm{R}}$ (in $\mathrm{MN}$ ), decreases with the demand plastic rotation $\theta_{\mathrm{p}}$ according to following experimental expression according to Eq.(A.12) of Eurocode EN 1998-3:

$V_{\mathrm{R}}=\frac{1}{\gamma_{\mathrm{el}}} \cdot\left[\frac{(h-x) \lambda_{1}}{2 L_{\mathrm{S}}}+\left(1-0.05 \lambda_{2}\right) \cdot\left[0.16 \lambda_{3}\left(1-0.16 \lambda_{4}\right) A_{\mathrm{c}} \sqrt{f_{\mathrm{cm}}}+V_{\mathrm{w}}\right]\right]$

where,

$\gamma_{\mathrm{el}}$ is a safety factor that is taken equal to 1.15 for primary seismic structural elements (due to scattering of the experimental values) and is taken 1.00 for secondary seismic members.

$\mathrm{x}$ is the compression zone depth (in meters) that is known by the "fiber analysis" of the section (Fig. 2),

$\lambda_{1}=\min \left(N, 0.55 A_{\mathrm{c}} f_{\mathrm{cm}}\right), N$ is the axial force in $\mathrm{MN}$ that is positive for compression, while when the axial force is tensional then it is taken zero, $A_{\mathrm{c}}=b_{\mathrm{W}} d$ for rectangular sections with $b_{\mathrm{W}}$ as width of compression zone and $d$ is the depth of the tension reinforcement in meters, $f_{\mathrm{cm}}$ is the concrete compressive strength (mean value) in MPa.

$\lambda_{2}=\min \left(5, \mu_{\Delta}^{\mathrm{p}}\right)$, where $\mu_{\Delta}^{\mathrm{p}}=\theta_{\mathrm{p}} / \theta_{\mathrm{u}}$.

$\lambda_{3}=\max \left(0.5,100 \rho_{\text {tot }}\right)$, where $\rho_{\text {tot }}$ is the total longitudinal reinforcement ratio (tensional, compression and intermediate), namely $\rho_{\mathrm{tot}}=\left(A_{\mathrm{s} 1}+A_{\mathrm{s} 2}+A_{\mathrm{sv}}\right) /\left(b_{\mathrm{w}} d\right)$

$$
\lambda_{4}=\min \left(5, a_{\mathrm{S}}\right), \text { where } a_{\mathrm{s}}=M /\left(h \cdot Q_{\mathrm{y}}\right)=L_{\mathrm{s}} / h \text { with } Q_{\mathrm{y}}
$$
is the contemporary shear force (Fig. 2).

$V_{\mathrm{W}}$ is the contribution of the transverse reinforcement to shear strength, taken as being equal to $V_{\mathrm{w}}=\rho_{\mathrm{w}} \cdot b_{\mathrm{w}} \cdot z \cdot f_{\mathrm{yw}, \mathrm{m}}$ for cross-section with rectangular web of width $b_{\mathrm{W}}$.

$\rho_{\mathrm{W}}$ is the transverse reinforcement ratio that is given by $\rho_{\mathrm{W}}=\left(A_{\mathrm{sw}} \cdot \ell_{\mathrm{W}}\right) /\left(h_{\mathrm{c}} \cdot b_{\mathrm{c}} \cdot s\right)$, where $\ell_{\mathrm{w}}$ is the total length of the stirrups, $A_{\mathrm{sW}}$ is the steel section area of the stirrup, $h_{\mathrm{c}}$ $\& b_{\mathrm{c}}$ the dimensions of the confined core of the section and $s$ is the centerline spacing of stirrups, Fig. (2).

\section{Final Moment-Chord Rotation Diagram $M-\theta$ of the Cantilever}

In order to define the final elastic-plastic diagram of Moment-Chord Rotation ( $M-\theta$ ) of a cantilever, it must be checked which type of failure precedes; flexure or shear? Thus, since the shear strength $V_{\mathrm{R}}$ is known by Eq.(8), the 


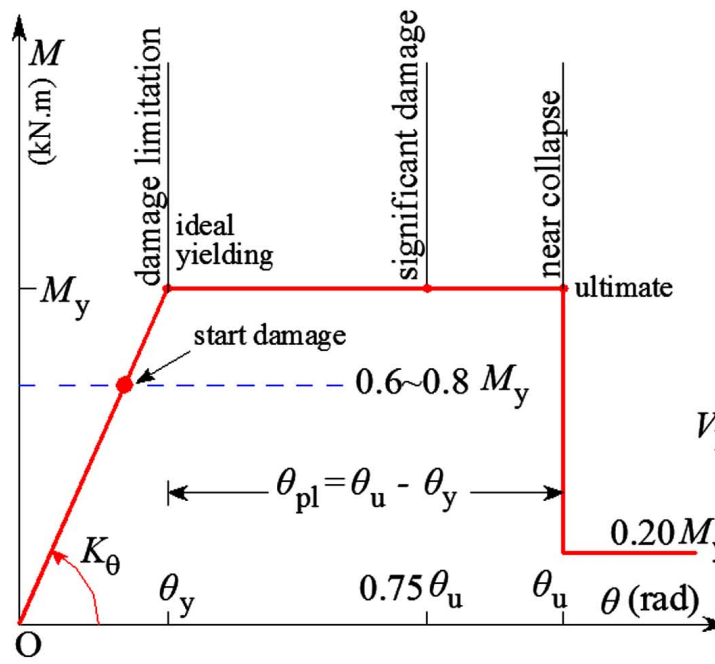

a. Diagram moment-chord rotation for ductile failure

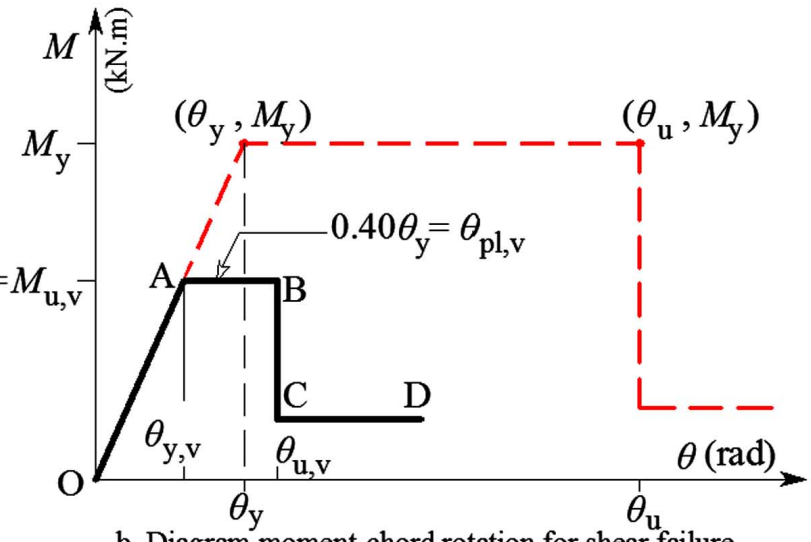

b. Diagram moment-chord rotation for shear failure

Fig. (6). Moment-chord rotation $(M-\theta)$ diagram of a cantilever

moment $M_{\mathrm{u}, \mathrm{v}}$ at the base of the cantilever due to $V_{\mathrm{R}}$ is easily calculated as $M_{\mathrm{u}, \mathrm{v}}=L_{\mathrm{s}} \cdot V_{\mathrm{R}}$. When $M_{\mathrm{u}, \mathrm{v}}$ is greater than the flexural yielding moment $M_{\mathrm{y}}$, then the flexural failure of the cantilever precedes the shear one. In that case, the final elastic-plastic diagram of Moment-Chord Rotation ( $M-\theta$ ) of a cantilever is given by Fig. (6a). However, when $M_{\mathrm{u}, \mathrm{v}}$ is smaller than the flexural yielding moment $M_{\mathrm{y}}$, then the shear failure of the cantilever precedes the flexural one. In the latter case, the final elastic-plastic diagram of Moment-Chord Rotation $(M-\theta)$ diagram of the cantilever is given as the curve OABCD of Fig. (6b) according to sect.7.2.4.2 of KANEPE 2012 [9].

\section{Effective Flexural Stiffness of Member Sections}

As it is clear, the above-mentioned cantilever (with constant geometric dimensions along its length) has linearelastic behavior until of the critical section at its base reaches the yielding state. Therefore, it can be concluded that the flexural stiffness $E_{\mathrm{c}} I$ of the member section can be constant for the total length of the member and thus its effective value ( $E_{\mathrm{c}} I_{\text {eff }}$ ) can be calculated from the combination of Eq.(5) and Fig. (1e). Thus the effective flexural stiffness $E_{\mathrm{c}} I_{\mathrm{eff}}$ is given by Eq.(9) according to sect.A.3.2.4(5)/ EN 1998-3:

$$
E_{\mathrm{c}} I_{\mathrm{eff}}=\frac{M_{\mathrm{y}} \cdot L_{\mathrm{s}}}{3 \cdot \theta_{\mathrm{y}}}
$$

Therefore, in the case of a real structural member (column or beam) that has plastic hinges at its two ends, the mean effective flexural stiffness $E_{\mathrm{c}} I_{\text {eff }}$ of the membersection can be estimated as the arithmetic mean of four different bend states, at the two ends of the element, for positive and negative sign of moments. This effective flexural stiffness $E_{\mathrm{c}} I_{\text {eff }}$ of the member cross-section is suitable for modelling its dynamic cyclic behavior when the building is subjected to earthquake loading. It should be noted that, the above-mentioned assumption about the $E_{\mathrm{c}} I_{\mathrm{eff}}$ is rational in the case when two plastic hinges are presented simultaneously at the two ends of a structural member. However, when no one (or one only) plastic hinge appears on the structural member then the previous assumption is not justifiable.

When the effective flexural stiffness $E_{\mathrm{c}} I_{\mathrm{eff}}$ by Eq.(9) is taken into account for all structural members of the building model, then it is expected that the periods of eigen-vibration of the model are changed and became longer. On the one hand, it is well-known that using this modelling there may be some mismatch at the beginning of the analysis compared to experimental results, but there is a very good agreement (with reference to seismic demand displacements and deformations) after the elements reach there damaged state. Besides, the total procedure is Displacement (and Deformation) Based Method. On the other hand, a possible result of this alteration of the periods of the models is that, the structure's model does not load seismically adequately, because the state of co-ordination, between the building's model and the seismic excitation is removed, since the model has high flexibility.

\section{Modelling of Masonry Infill Walls}

According to the guidelines of the KANEPE 2012 [9], the modelling technique for masonry infill walls that will be adopted depends on the selection of the seismic performance level for which the structure will be checked. In particular:

For the "Damage Limitation" limit state: In this case, the behavior of the structure is considered practically linearelastic, thus, the masonry infill walls can be modeled with two equivalent diagonal bars, with simple hinges at their ends and with linear behavior. According to the specifications of KANEPE 2012 [9], each bar must have rectangular 
cross-section and axial stiffness $E A_{\text {eff }}=0.50 E_{\mathrm{w}} A_{\mathrm{W}}$, where $A_{\mathrm{W}}=w \cdot t_{\mathrm{W}}$ is the section area of the equivalent bar, $w$ is the effective width, $t_{\mathrm{W}}$ is the effective thickness of the wall and $E_{\mathrm{W}}$ is the Elasticity Modulus of the masonry infill wall.

For "Significant Damage" limit state: In this case, the behavior of the structure is non-linear, thus, the masonry infill walls can be modeled by two equivalent diagonal bars with simple hinges at their ends and with one-sided (in compression only) non-linear behavior. According to the specifications of KANEPE 2012 [9], each diagonal bar must have a rectangular cross-section with axial-stiffness (in compression only) equal to $E A_{\mathrm{eff}}=0.68 E_{\mathrm{W}} A_{\mathrm{W}}$.

For "Near Collapse" limit state, according to sect.7.4.1b of KANEPE 2012 [9], all masonry infill walls should be ignored from the structural model.

The effective width $w$ of the equivalent diagonal bar of a masonry infill wall can be calculated using the following equation:

$w=0.175 \cdot L \cdot \lambda \cdot \lambda_{\mathrm{h}}^{-0.4}$

where, $L$ is the length of the diagonal direction of each masonry infill wall and $\lambda_{\mathrm{h}}$ is a factor that can be calculated by Eq.(11) [13-16], while $\lambda$ is a reduction factor that depends on size of the opening that may exists, while it is given by Eq.(12) [17-23].

$\lambda_{\mathrm{h}}=h \cdot \sqrt[4]{\frac{E_{\mathrm{W}} \cdot t_{\mathrm{W}} \cdot \sin 2 \alpha}{4 E_{\mathrm{c}} I_{\mathrm{eff}, \mathrm{m}} \cdot h_{\mathrm{w}}}}$

where $E_{\mathrm{c}} I_{\mathrm{eff}, \mathrm{m}}$ is the arithmetic mean of the effective flexural stiffness of the two column sections that are given by Eq.(9), $h$ is the storey high, $h_{\mathrm{w}}$ is the masonry infill wall pure high, $\alpha$ is the slope (referring to horizontal direction) of the diagonal bar.

$\lambda=1-2 \alpha_{\mathrm{w}}^{0.54}+\alpha_{\mathrm{w}}^{1.14}$

where $\alpha_{\mathrm{w}}=A_{\text {open }} / A_{\mathrm{wall}}, A_{\mathrm{open}}$ is the area of opening and $A_{\text {wall }}$ is the masonry infill wall area.

It is worth noting that, according to the guidelines of KANEPE 2012 [9], the Modulus of Elasticity $E_{\mathrm{w}}$ of the masonry infill wall can be estimating by Eq.(13):

$E_{\mathrm{W}}=K_{\mathrm{E}} \cdot f_{\mathrm{wc}}$

where,

$K_{\mathrm{E}}$ is a factor between 500 and 1000 ,

$f_{\mathrm{wc}}$ is the mean compressive strength of the masonry infill wall (in $\mathrm{MPa}$ ), along the diagonal direction. Approximately, according to KANEPE 2012 [9], the value of $f_{\mathrm{wc}}$ can be estimated via the following relationship: $f_{\mathrm{wc}}=\lambda_{\mathrm{s}} \cdot \lambda_{\mathrm{m}} \cdot \lambda_{\mathrm{c}} \cdot k \cdot f_{\mathrm{bc}}^{0.7} \cdot f_{\mathrm{mc}}^{0.3}$

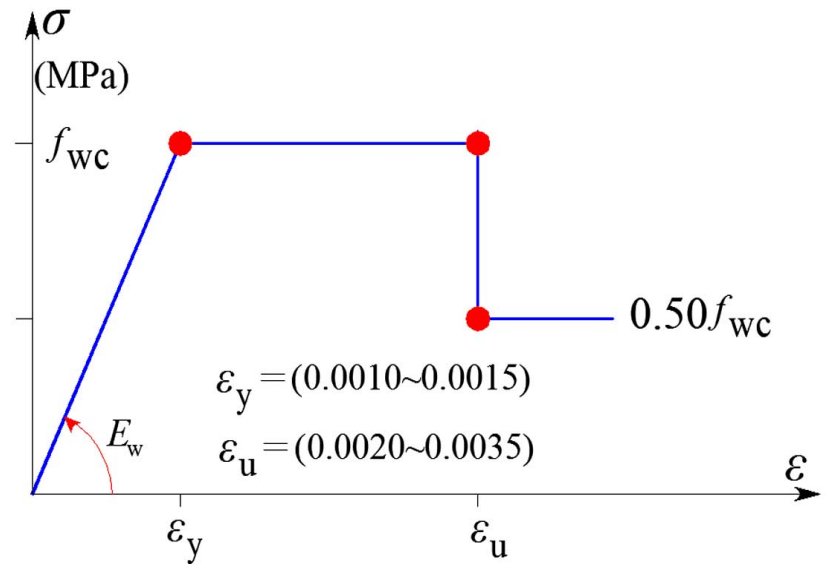

Fig. (7). One-sided non-linear diagram $\sigma-\varepsilon$ of the compressive diagonal bar of the masonry infill wall.

where,

$\lambda_{\mathrm{s}}$ is a factor that is taken equal to 0.7 and via this factor the masonry infill wall's lateral force is converted to diagonal force of the wall,

$\lambda_{\mathrm{m}}$ is a factor that is taken equal to 1.5 and via this factor the characteristic strength of the masonry infill wall is converted to mean strength,

$\lambda_{\mathrm{c}}$ is a factor that is taken equal to 1.2 and via this factor the wall's strength is increased thanks to bounding r/c frame consisting of the two columns and a beam.

$k$ is a factor with value between 0.35 and 0.55 and is dependent on the bricks and mortar,

$f_{\mathrm{bc}}$ is the mean compressive strength of the brick (about 5.5MPa for a common Greek brick),

$f_{\mathrm{mc}}$ is the mean compressive strength of the mortar (about 3.5 MPa for a common Greek mortar),

For "Significant Damage" limit state, according to KANEPE 2012 [9], the one-sided non-linear stress-strain diagram $\sigma-\varepsilon$ of the compressive diagonal bar of the masonry infill wall can be represented by the one shown in Fig. (7).

\section{EXAMPLE}

\section{Data}

Consider the spatial asymmetric three-storey r/c building (Fig. 8) that has been designed according to Eurocodes EN 1998-1 \& EN 1992, using concrete category C25/30, steel B500c and their other properties according to Table 3.1 of EN 1992. There are eight columns (C1-C8) with crosssection $(0.55 \mathrm{~m}) \mathrm{x}(0.55 \mathrm{~m})$ and two $\mathrm{r} / \mathrm{c}$ walls $(\mathrm{W} 1-\mathrm{W} 2)$ with cross-section $(0.30 \mathrm{~m}) \times(2.00 \mathrm{~m})$ in each storey. Moreover, there is an $\mathrm{r} / \mathrm{c}$ slab with an edge cantilever $2.00 \mathrm{~m}$ in length along the perimeter, which ensures diaphragmatic action around vertical axis. Each diaphragm has translational mass 
$m=400 \mathrm{t}$ that is concentrated at its geometric centre. Thus, the total mass of the building is $m_{\mathrm{tot}}=3 \mathrm{~m}$. Each diaphragm has mass moment of inertia $J_{\mathrm{m}}$ around the vertical axis passing through its centre of mass CM, which has been calculated based on the diaphragm dimensions as $J_{\mathrm{m}}=23932.34 \mathrm{tm}^{2}$; hence, the radius of gyration $r$ of the diaphragm is $r=\sqrt{J_{\mathrm{m}} / m}=7.74 \mathrm{~m}$. Each storey has a height of $4.00 \mathrm{~m}$ (Fig. 9). The above-mentioned $\mathrm{r} / \mathrm{c}$ building has been designed for Ductility Class High (DCH) according to Eurocode EN 1998-1. As effective stiffness of the member sections of the building has been taken the $50 \%$ of the stiffness of the geometric section, for all linear analyses according to sect.4.3.1(7) of EN 1998-1. Member details are shown in Fig. (9).

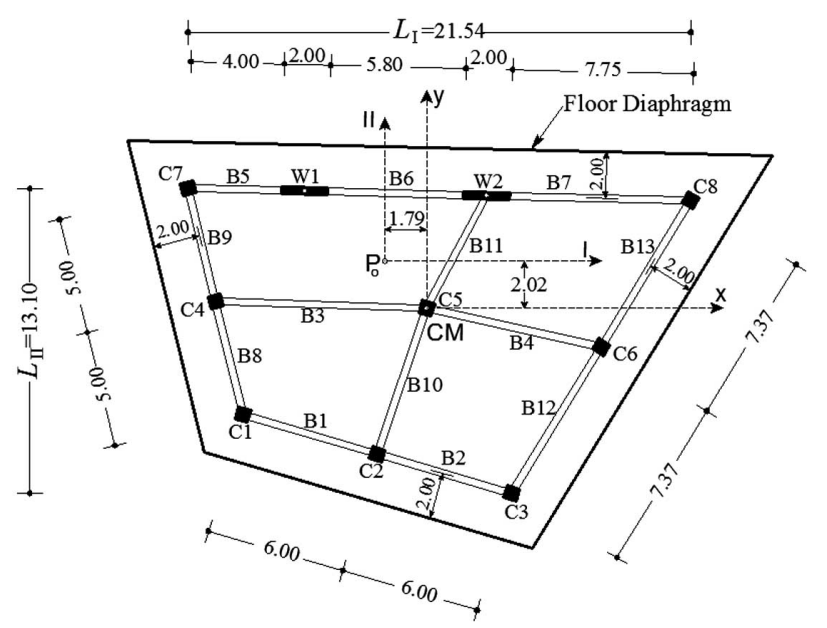

Fig. (8). Plan of an asymmetric three-storey $\mathrm{r} / \mathrm{c}$ building.

It is worth noting that, since this building is not singlestorey, equation Eq.(4.1b) of EN/1998-1 can not be applied to check the building regularity in-plan. Also, the use of the moments of inertia of the vertical member sections according to sect.4.2.3.2(9) of EN 1998-1 leads to unacceptable results $[24,25]$. Moreover, the sect.4.2.3.2(8b) of Eurocode EN 1998-1 permits the use of the more suitable equations specified in the National Annexes, such as Hellenic National Annex of EN 1998-1. In order to check the regularity (in-plan) of the above-mentioned three-storey $\mathrm{r} / \mathrm{c}$ building the provisions of the Hellenic National Annex of EN 1998-1 are used because it is the only documented solution mathematically [24-27], (Fig. 8). To do this check, the following three parameters have been calculated; (a) the fictitious centre of stiffness $P_{\mathrm{O}}$ in-plan, (b) the two fictitious horizontal principal directions $P_{\mathrm{O}} \mathrm{I} \& P_{\mathrm{O}} \mathrm{II}$ of the building and (c) the two torsional-stiffness radii $\rho_{\mathrm{I}} \& \rho_{\mathrm{II}}$ respectively. Thus, the two torsional-stiffness radii arise as $\rho_{\mathrm{I}}=9.81 \mathrm{~m}(>r=7.74 \mathrm{~m}) \&$ $\rho_{\text {II }}=6.23 \mathrm{~m}(<r=7.74 \mathrm{~m})$, so, the above-mentioned $\mathrm{r} / \mathrm{c}$ building is torsionally-flexible, because one torsionalstiffness radius is less than the diaphragm radius of inertia, $\rho_{\mathrm{II}}<r=7.74,[27]$.

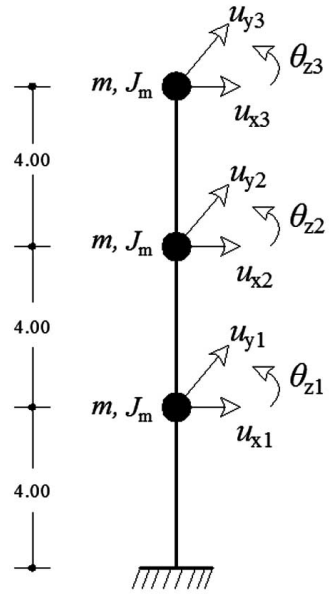

Materials: Concrete C25/30, Steel B500c

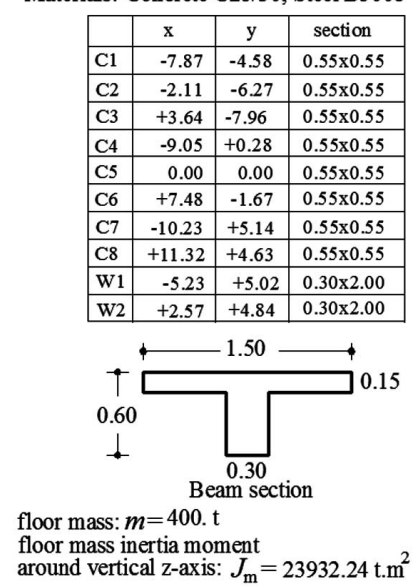

Fig. (9). Degrees of freedom of a vertical cantilever beam. Details of cross-section of beams and columns.

Next, the maximum behavior factor of the torsional building is $q=3.00$ for Ductility Class High is specified according to Eurocode EN 1998-1. The floor masses have been concentrated and positioned at the geometric centre $\mathrm{CM}$ of the floor-diaphragms, while the accidental eccentricities have been taken into account via using of external floor static moments around a vertical axis with the same sign at all floors. According to sect. 4.3.6.3.1(4) of EN 1998-1, double accidental eccentricity should be considered due to irregular distribution of masonry infill walls in-plan.

$e_{\mathrm{a}, \mathrm{I}}=0.10 \cdot L_{\mathrm{a}, \mathrm{II}}=0.10 \cdot 13.10=1.31 \mathrm{~m}$

$e_{\mathrm{a}, \mathrm{II}}=0.10 \cdot L_{\mathrm{a}, \mathrm{I}}=0.11 \cdot 21.54=2.15 \mathrm{~m}$

where $L_{\mathrm{a}, \mathrm{I}} \& L_{\mathrm{a}, \mathrm{II}}$ are the building external dimensions along the principal axes I \& II (Fig. 8).

Accidental eccentricities $e_{\mathrm{a}, \mathrm{I}} \& e_{\mathrm{a}, \mathrm{II}}$ are used for the calculation of the external floor static moments $M_{\mathrm{I}, i}$ \& $M_{\mathrm{II}, i}$ around a vertical axis with the same sign at all floors, according to following expressions:

$M_{\mathrm{II}, i}= \pm F_{\mathrm{II}, i} \cdot e_{\mathrm{a}, \mathrm{I}}$

$M_{\mathrm{I}, i}= \pm F_{\mathrm{I}, i} \cdot e_{\mathrm{a}, \mathrm{II}}$

where $F_{\mathrm{I}, i}, F_{\mathrm{II}, i}$ are the external static forces of storey $i$, along the principal horizontal I and II-axes of the building.

The design base shears, $V_{\mathrm{O}, \mathrm{I}} \& V_{\mathrm{O}, \text { II }}$, have been calculated first, for both principal horizontal directions I \& II by the following relationships:

$V_{\mathrm{O}, \mathrm{I}}=m_{\mathrm{tot}} \cdot S_{\mathrm{a}}\left(T_{\mathrm{I}}\right) / q$
$V_{\mathrm{O}, \mathrm{II}}=m_{\mathrm{tot}} \cdot S_{\mathrm{a}}\left(T_{\mathrm{II}}\right) / q$ 
where $T_{\mathrm{I}}$ (and $T_{\mathrm{II}}$ ) are the building fundamental periods for pure translational vibration along I and II-axes and $S_{\mathrm{a}}(T)$ is the elastic spectral acceleration. Next, each design base shear has been distributed in elevation according to building's translational fundamental mode-shape in order to calculate the external floor static forces for each principal direction.

The seismic action (namely, the two seismic horizontal components) is oriented along the two principal horizontal I $\&$ II-axes of the building. Since the seismic components are "statistically independent" (sect.3.2.2.1(3)) of Eurocode EN/1998-01, the response spectrum analysis is applied for each principal horizontal building's direction separately, using the design acceleration spectrum of EN 1998-1 with $A=0.16 \mathrm{~g}$ and $q=3.00$. In the loading case along I-axis, the floor masses are located at the geometric centres of the diaphragms and the accidental eccentricity has been taken into account via floor external moments $\pm M_{\mathrm{I}, i}$ (and $\pm M_{\mathrm{II}, i}$ for loading along II-axis) according to sect.4.3.3.3.3(2) of EN 1998-1. A superposition on the results of the previous analyses, has been taken place. Afterwards, in order to get the results of analysis due to spatial action of the two horizontal seismic components, the Square Root of Sum of Squares (SRSS) rule has been used and all results have been considered acting simultaneously. With reference to gravity loads, self-weights of $\mathrm{r} / \mathrm{c}$ members have been considered, as well as additional uniform permanent loads, such as $2.00 \mathrm{kN} / \mathrm{m}^{2}$ for slabs, live-loads $2.00 \mathrm{kN} / \mathrm{m}^{2}$ and $5.00 \mathrm{kN} / \mathrm{m}^{2}$ for slabs and slab-cantilevers, respectively. All beams carry a masonry infill wall that has self-weight $3.60 \mathrm{kN}$ per square meter of its vertical area. All alternative cases of gravity load cases have been examined, while during the seismic action, gravity loads $G+0.30 Q$ have been considered for all beams. The design of the $\mathrm{r} / \mathrm{c}$ building has been performed according to Eurocodes EN 1998-1 and EN 1992. Following the member design, in order to calculate the moment-curvature $(M-\varphi)$ diagrams of all critical $\mathrm{r} / \mathrm{c}$ sections, all these sections have been analyzed using the "fiber elements" (via XTRACT software [10]) using mean strength values of materials with their suitable stress-strain $(\sigma-\varepsilon)$ diagrams (Figs.3-5). For each one critical section, an equivalent ideal perfectly elastic-plastic moment-curvature $(M-\varphi)$ diagram has been calculated and next, the final Moment-Chord Rotation $(M-\theta)$ diagrams of each member has been obtained according to Fig. (6a,b). Thus, inelastic springs with the derived $M-\theta$ characteristics were added in the model at the ends of each of the beams and columns of the structure. It is worth noting that columns C5 \& C6 failed in shear (representing 15\% of the vertical $\mathrm{r} / \mathrm{c}$ members) despite the fact that all relative provisions of DCH category of Eurocode EN 1998-1 have been applied. Moreover, $40 \%$ of the beam-sections failed in shear. Note that the building has 39 beams, 13 beams per storey, and therefore 78 end beam-end-sections. Two checks (for positive and negative sign) for each critical section, namely 156 checks, have been performed, in the 62 of which, the shear failure precedes the flexural one. This point is important and, for this particular building, indicates a deficiency of the design according to Eurocode EN/1998-01. In addition, all structural members have been supplied with effective flexural stiffness $E_{\mathrm{c}} I_{\mathrm{eff}}$, where it is constant of all member's length, according to Eq.(9). The values of $E_{\mathrm{c}} I_{\mathrm{eff}}$, given by Eq.(9), have been ranged from $0.09 E_{\mathrm{c}} I_{\mathrm{g}}$ to $0.24 E_{\mathrm{c}} I_{\mathrm{g}}$ (with mean value $0.12 E_{\mathrm{c}} I_{\mathrm{g}}$ ) for all columns, while for beams from $0.11 E_{\mathrm{c}} I_{\mathrm{g}}$ to $0.47 E_{\mathrm{c}} I_{\mathrm{g}}$ (with mean value $0.28 E_{\mathrm{c}} I_{\mathrm{g}}$ ), where $I_{\mathrm{g}}$ is the moment of inertia of the geometric section of the member.

After of all above-mentioned data, must be checked if this irregular in-plan, three-storey $\mathrm{r} / \mathrm{c}$ building satisfies the three seismic targets (Damage Limitation, Significant Damage and Near Collapse) for the respective three seismic actions (Frequent Earthquake, Design Basis Earthquake and Maximum Capable one) according to seismic performance matrix.

\section{Modelling of the Seismic Excitation}

The seismic demand inelastic floor displacements have been obtained through non-linear response-history analysis (using SAP2000v14 software) using suitable pairs of accelerograms for various levels of seismic action. In order to simulate the seismic action for the needs of the present paper, seven pairs of horizontal artificial seismic accelerograms have been developed. Each used accelerogram is compatible (for equivalent viscous ratio damping 0.05) with the respective design elastic response spectrum that is proposed by Eurocode EN 1998-1 for soil category $D$. The two accelerograms of each pair are practically uncorrelated between them and act simultaneously. Moreover, each accelerogram has many of the characteristic properties of the Hellenic earthquakes, according to the database of the Hellenic earthquake records [28].

Hilber et al., [29] step-by-step numerical method of integration has been used in the non-linear response-history analyses using coefficient $\alpha=-0.15$, because it is very stable. If $\alpha=0$ then this method coincides with the Newmark one. All accelerograms are digitized every $0.005 \mathrm{~s}$, have total duration $25.00 \mathrm{~s}$ and the strong motion duration is more than 18.00s. These artificial accelerograms are better than the natural ones because their frequency content (Fig. 10) is richer than the frequency content of the natural elastic response spectra. Moreover, these artificial accelerograms possess adequate strong motion duration, adequate number of significant dynamic loading cycles, as well as adequate Arias Intensity according to Hellenic strong earthquakes [28].

\section{Modelling of Masonry Infill Walls}

For the needs of the present study of the three-storey building, the mean compressive strength of a Greek brick and a Greek mortar are considered to be $f_{\mathrm{bc}}=5.5 \mathrm{MPa}$ and $f_{\mathrm{mc}}=3.5 \mathrm{MPa}$, respectively; thus, the mean diagonal compressive strength of the masonry infill wall is given by Eq.(14): 


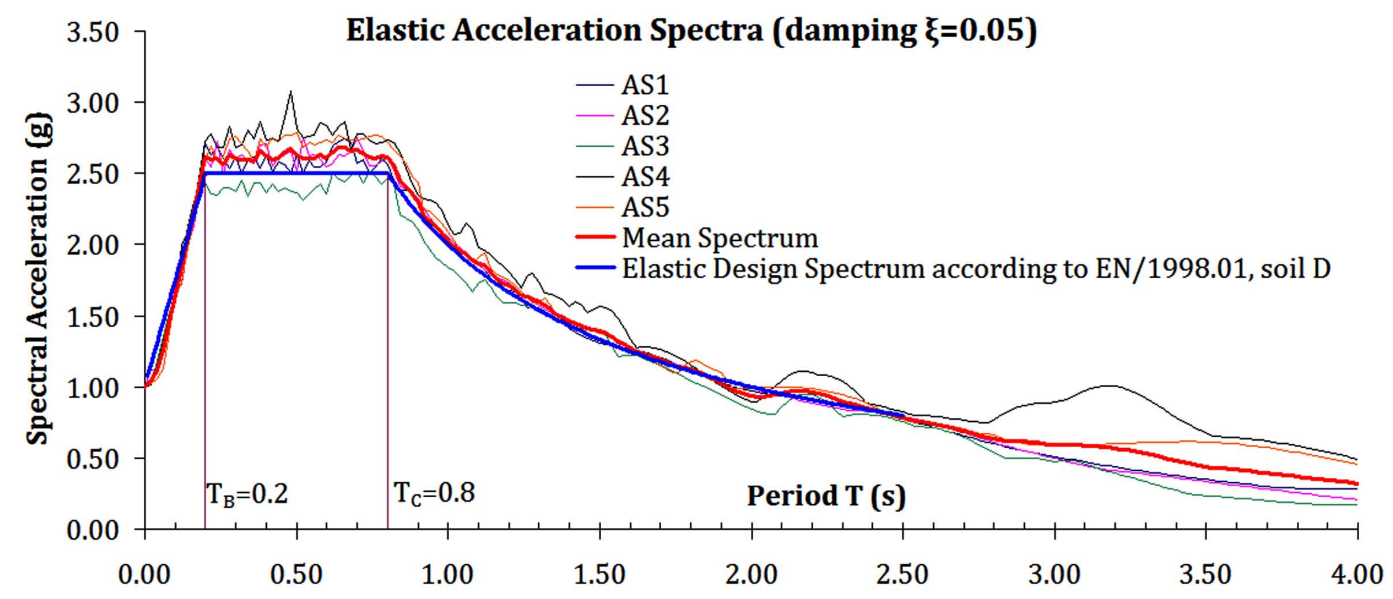

Fig. (10). Acceleration Spectra of five artificial accelerograms those are compatible with the design acceleration spectrum according to Eurocode EN 1998-1, soil category D.

$$
f_{\mathrm{wc}}=0.7 \cdot 1.5 \cdot 1.2 \cdot 0.35 \cdot 5.5^{0.7} \cdot 3.5^{0.3}=2.12 \mathrm{MPa}
$$

It is common to consider the mean compressive strength calculated above along the diagonal direction of the masonry infill wall as a lower-bound limit, while an upper-bound limit is taken as $3.00 \mathrm{MPa}$. Moreover, the Modulus of Elasticity $E_{\mathrm{W}}$ of a masonry infill wall can be estimated by Eq.(13):

$$
E_{\mathrm{W}}=(\text { from } 500 \text { to } 1000) \cdot 2.12=\text { from } 1060 \text { to } 2120 \mathrm{MPa}
$$

Therefore, for the next needs of this analysis, the values was set to the arithmetic mean $E_{\mathrm{W}}=1590 \mathrm{MPa}$. In order to calculate the effective width $w$ of the equivalent diagonal bar for the masonry infill wall C3-B12-C6 an effective thickness $t_{\mathrm{W}}=0.19 \mathrm{~m}$ was considered, Fig. (8). The effective flexural stiffness $E_{\mathrm{c}} I_{\mathrm{eff}}$ of the columns C3 \& C6 is $25908.50 \mathrm{kN} \cdot \mathrm{m}^{2}$ and $47846.42 \mathrm{kN} \cdot \mathrm{m}^{2}$, respectively. Thus, the arithmetic mean is $E_{\mathrm{c}} I_{\mathrm{eff}, \mathrm{m}}=36577.46 \mathrm{kN} \cdot \mathrm{m}^{2}$ to apply Eq.(11) and the diagonal length is $L=\sqrt{4^{2}+7.37^{2}}=8.39 \mathrm{~m}$, since $h=4.00 \mathrm{~m}$ and horizontal length $7.37 \mathrm{~m}$. The angle of the diagonal bar is calculated geometrically as $\hat{a}=28.50^{\circ}$, whilst coefficient $\lambda_{\mathrm{h}}$ is calculated by Eq.(11), using pure masonry high $h_{\mathrm{W}}=3.40 \mathrm{~m}$ :

$\lambda_{\mathrm{h}}=h \cdot \sqrt[4]{\frac{E_{\mathrm{W}} \cdot t_{\mathrm{W}} \cdot \sin 2 \alpha}{4 E_{\mathrm{c}} I_{\mathrm{eff}, \mathrm{m}} \cdot h_{\mathrm{w}}}}=4 \cdot \sqrt[4]{\frac{1590000 \cdot 0.19 \cdot \sin (2 \cdot 28.5)}{4 \cdot 36577.46 \cdot 3.40}}=3.38$

Therefore, in the case when there are no openings on the masonry infill wall does not exist $(\lambda=1.00)$, then the effective width $w$ of the equivalent diagonal bar for the masonry infill wall is given by Eq.(10):

$w=0.175 \cdot L \cdot \lambda \cdot \lambda_{\mathrm{h}}^{-0.4}=0.175 \cdot 8.39 \cdot 1.00 \cdot 3.38^{-0.40}=0.90 \mathrm{~m}$

Thus, in this case, the section area of the equivalent diagonal wall bar is:

$$
A_{\mathrm{W}}=w \cdot t_{\mathrm{W}}=0.90 \cdot 0.19=0.171 \mathrm{~m}^{2}
$$

For the needs of this example, all masonry infill walls were considered solid, without openings, except masonry infill walls C1-C2-C3-C6-C8, C4-C5-C6 and C2-C5-W2, which have large opening with coefficient $\alpha_{\mathrm{W}}=0.25$. Thus, the reduction factor is given as:

$$
\lambda=1-2 \alpha_{\mathrm{W}}^{0.54}+\alpha_{\mathrm{W}}^{1.14}=1-2 \cdot 0.25^{0.54}+0.25^{1.14}=0.26
$$

In the case when there is an opening on the masonry infill wall, then the effective width $w$ of the equivalent diagonal bar and the section area, respectively, are given as:

$$
w=0.175 \cdot L \cdot \lambda \cdot \lambda_{\mathrm{h}}^{-0.4}=0.175 \cdot 8.39 \cdot 0.26 \cdot 3.38^{-0.40}=0.23 \mathrm{~m}
$$

$A_{\mathrm{W}}=w \cdot t_{\mathrm{W}}=0.23 \cdot 0.19=0.044 \mathrm{~m}^{2}$

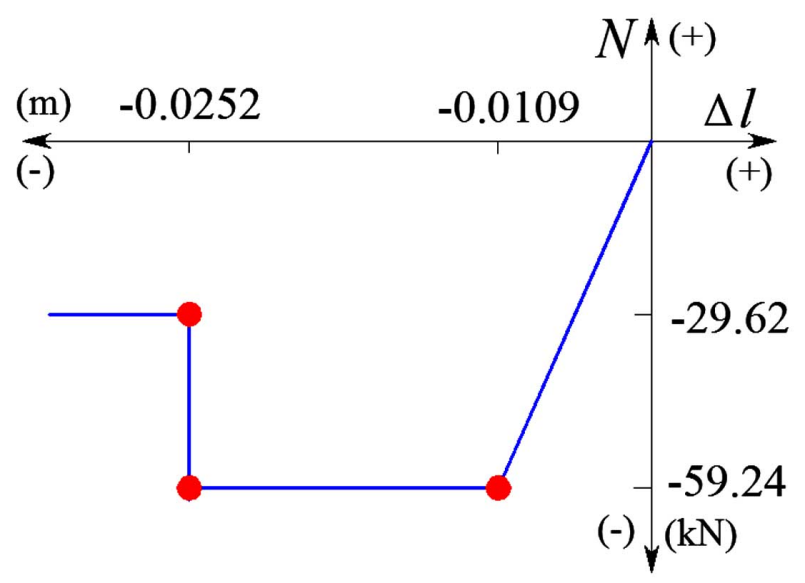

Fig. (11). Non-linear axial force-lengthening diagram of diagonal compressive bar with one-sided operation for masonry infill wall C3-C6.

For "Significant Damage" limit state of the seismic performance matrix, each masonry infill wall is simulated with two one-sided (in compression only) non-linear diagonal bars, having all of them the following axial-stiffness: 
Table 1. Periods of the Three-Storey Building.

\begin{tabular}{|l|c|c|c|c|}
\hline Periods & $\begin{array}{c}\text { Model of bare frame } \\
\text { (without infill walls) } \\
\text { and with stiffness of } \\
\text { geometric cross- } \\
\text { section }\end{array}$ & $\begin{array}{c}\text { Model of bare frame (without infill } \\
\text { walls) and with 50\% reduction of the } \\
\text { cross-section stiffness (for Design, } \\
\text { sect.4.3.1(7)/EN 1998-1) }\end{array}$ & $\begin{array}{c}\text { Model of infilled frame and } \\
\text { with effective cross-section } \\
\text { stiffness (for NLRHA, DBE) }\end{array}$ & $\begin{array}{c}\text { Model of bare frame (without } \\
\text { infill walls) and with effective } \\
\text { cross-section stiffness (for } \\
\text { NLRHA, MCE) }\end{array}$ \\
\hline \hline $\mathrm{T}_{1}(\mathrm{~s})$ & 0.63 & 0.89 & 0.48 & 1.71 \\
\hline $\mathrm{T}_{2}(\mathrm{~s})$ & 0.49 & 0.69 & 0.30 & 1.38 \\
\hline
\end{tabular}

$E A_{\mathrm{eff}}=0.68 E_{\mathrm{E}} A_{\mathrm{W}}=0.68 \cdot 1590000 \cdot 0.044=47572.8 \mathrm{kN}$

Taking into account the stress-strain $(\sigma-\varepsilon)$ diagram of Fig.(7), the axial yield strain $\varepsilon_{\mathrm{y}}$ and the ultimate strain $\varepsilon_{\mathrm{u}}$ are calculated as:

$\varepsilon_{\mathrm{y}}=f_{\mathrm{wc}} / E_{\mathrm{E}}=2.12 / 1590=0.0013, \quad \varepsilon_{\mathrm{u}}=0.0030$

Therefore, the yielding axial force is $N_{\mathrm{y}}=\varepsilon_{\mathrm{y}} \cdot E A_{\mathrm{eff}}=0.0013 \cdot 45572.8=59.24 \mathrm{kN}$, while the yielding lengthening is $\Delta \ell_{\mathrm{y}}$ and the failure lengthening is $\Delta \ell_{\mathrm{u}}$ are calculated.

$\Delta \ell_{\mathrm{y}}=\varepsilon_{\mathrm{y}} \cdot L=0.0013 \cdot 8.39=0.0109 \mathrm{~m}$

$\Delta \ell_{\mathrm{u}}=\varepsilon_{\mathrm{u}} \cdot L=0.0030 \cdot 8.39=0.0252 \mathrm{~m}$

Thus, the non-linear diagram of the one-sided equivalent diagonal bar for masonry infill wall C3-C6 that has a large opening is given in Fig. (11), while the diagrams $N-\Delta \ell$ of the other masonry infill walls of the three-storey building are calculated with same procedure.

It is clear that the masonry infill walls and the effective flexural stiffness of the member sections affect significantly the fundamental eigen-periods of the structural model. Indeed, in the Table 1, the first eigenperiods of vibration of the building are shown for various models of the three-storey building.

\section{Non-Linear Static Analysis of Spatial Model without Ma- sonry Infill Walls}

According to sect.4.4.4.1(2)P of Eurocode EN 1998-3, in the case of irregular in-plan buildings, such as torsionallyflexible buildings, a suitable spatial model of the building has to be used for the non-linear static (pushover) analysis. However, no-specific details are given. Recently, a documented mathematical methodology about the application of the non-linear static analysis for those irregular buildings, taking into account fully the floor rotations around vertical axis, has been proposed [5-7]. In the present article though, the non-linear response-history analysis has been applied on a spatial model of the building. Moreover, in each case and according to sect.4.3.3.4.2.1(2)P of EN 1998-1, two separately non-linear static analyses of the spatial building model has to be performed along the two principal directions, applying the lateral static forces at the centre of mass (CM) of the floor-diaphragms. As result of this, the capacity curves of the building (without masonry infill walls) obtained by pushover spatial analysis, along the building principal axes I $\&$ II, are shown in Figs. $(\mathbf{1 2}, \mathbf{1 3})$.

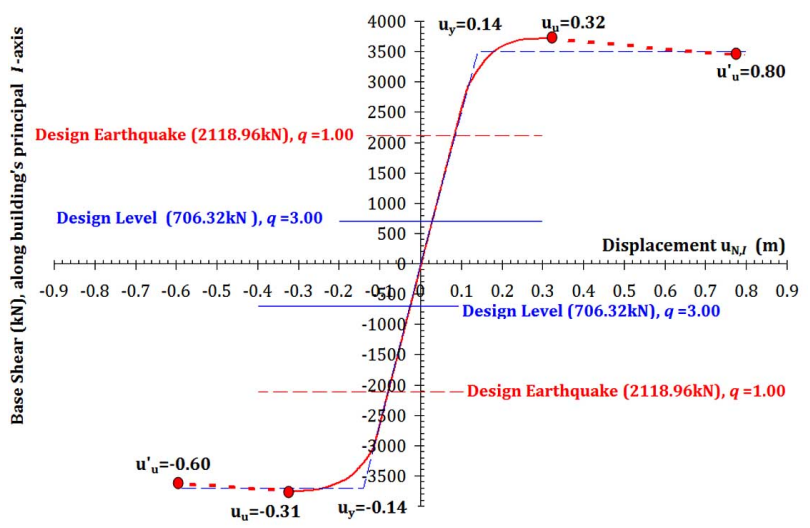

Fig. (12). Pushover Curve due to loading at CM, along building's principal $I$-axis. (Building without infill walls).

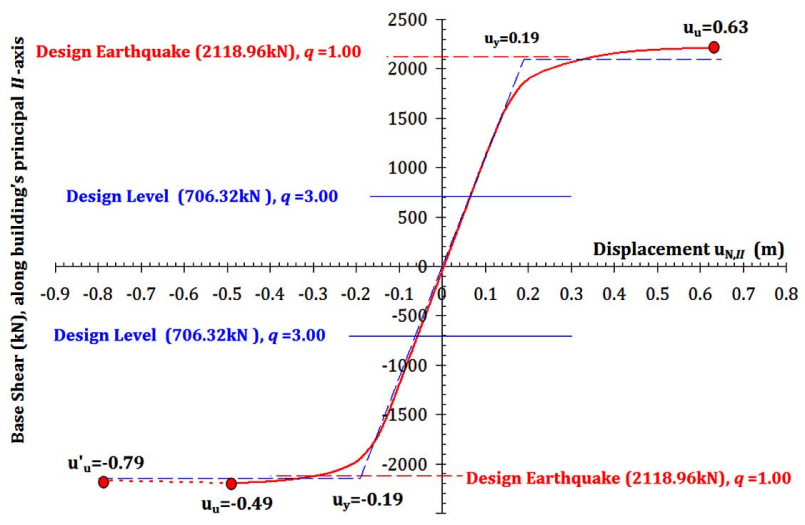

Fig. (13). Pushover Curve due to loading at CM, along building's principal $I I$-axis. (Building without infill walls).

\section{Non-Linear Response-History Analysis of Spatial Model with and without Masonry infill Walls}

Seven pairs of artificial uncorrelated accelerograms according to sect.3.2.2.1(3)P of EN 1998-1) are used in the non-linear response-history analyses. Accelerograms of the pairs (AS1,AS4), (AS1,AS5), (AS1,AS2), (AS3,AS4), (AS4,AS5), (AS1,AS3) and (AS2,AS4) have elastic acceleration spectra that are shown in Fig. (10). Each pair has been orientated along the principal building directions II and I. Four combinations of signs $(++,+-,-+,--)$ have been ex- 


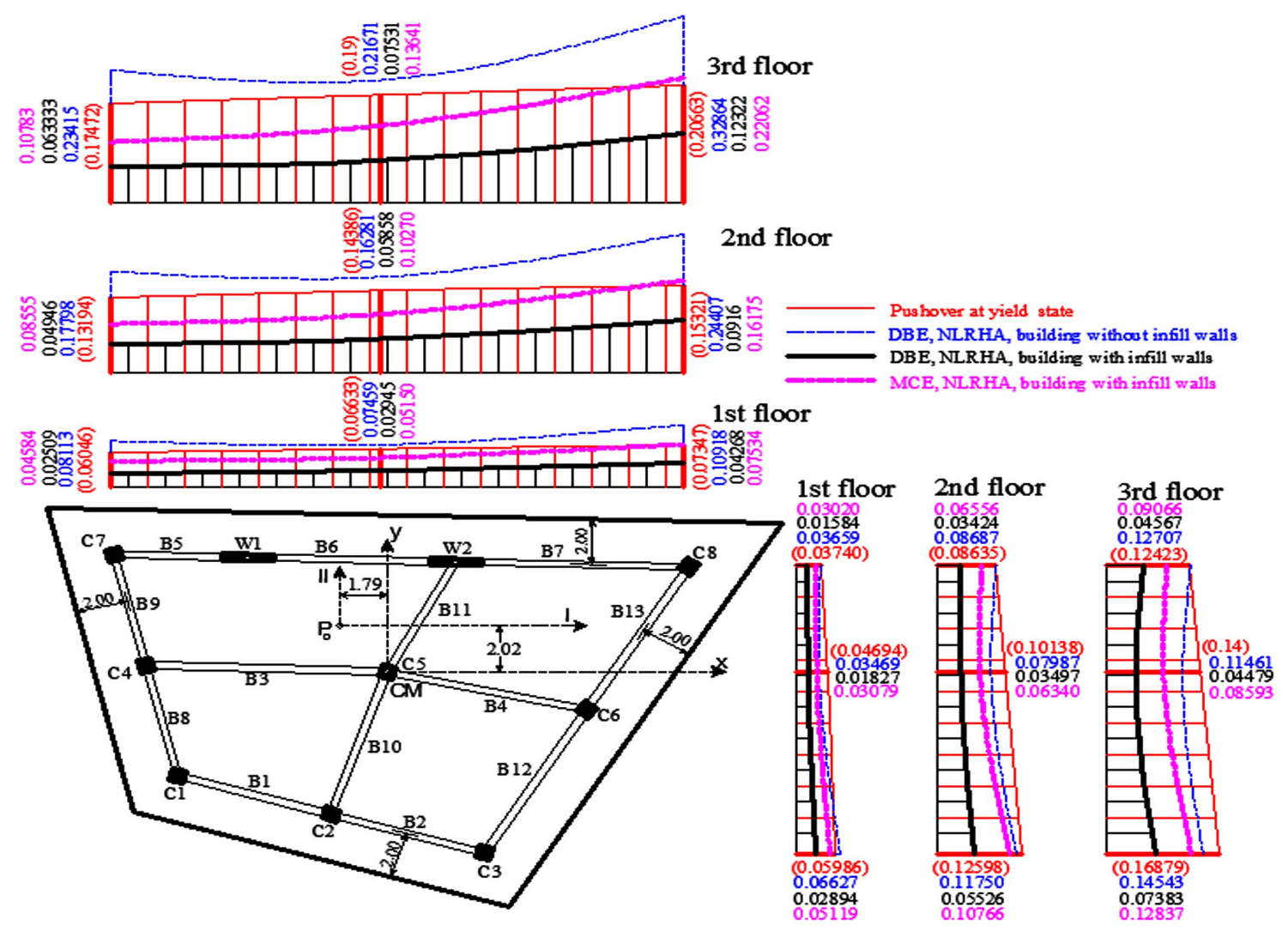

Fig. (14). Extreme displacements by non-linear response history-analysis (without accidental eccentricity).

amined for each pair. Moreover, a second orientation that was rotated at $45^{\circ}$ relative to principal I-axis has been examined. The accidental eccentricity has been taken into account via an equivalent mean floor external moments $M_{\mathrm{m}, \mathrm{i}}$, which can be estimated by Eq.(15) in order to minimize the computational cost, [6]:

$M_{\mathrm{m}, i}= \pm \sqrt{M_{\mathrm{I}, i}^{2}+M_{\mathrm{II}, i}^{2}}=\sqrt{\left(F_{\mathrm{I}, i} \times e_{\mathrm{a} i, \mathrm{II}}\right)^{2}+\left(F_{\mathrm{II}, i} \times e_{\mathrm{a} i, \mathrm{I}}\right)^{2}}$

It is worth noting that, forces $F_{\mathrm{I}, i}$ and $F_{\mathrm{II}, i}$ of Eq. (19) are changed with reference to peak ground acceleration $A_{\mathrm{ef}, j}$ of $j$ discrete seismic levels of the seismic performance matrix. First, a static pushover analysis was applied on the building using the total of gravity loadings, $G+0.3 Q$. Next, on the deformed building due to gravity loads, a new static pushover analysis was performed with static floor moments $M_{\mathrm{m}, \mathrm{i}}$. Afterwards, on the last deformed building's model, non-linear response-history analyses were performed, where the floor masses were located at the geometric centres of the diaphragms. All previous analyses were repeated using negative sign of the static floor moments $M_{\mathrm{m}, \mathrm{i}}$. The number of non-linear response-history analysis was 56 for each level of seismic action [ 4 combinations of signs, 7 pairs of acceleration and 2 orientations of seismic action (the first orientation is along principal axes I and II of the building and the second orientation is with $45^{\circ}$ angle); total, $4 \times 7 \times 2=56$ solutions per seismic action level].

An envelope of the results of all previous analyses was created, while the extreme results have been considered that act simultaneously. The demand seismic inelastic floor displacements (without the influence of accidental eccentricity) are shown in Fig. (14). The accidental eccentricity gives an increase of $0.01-0.02 \mathrm{~m}$ at the perimetric demand floor displacements. An earthquake that has mean return period 475 years has been considered as a Design Basis Earthquake (DBE). If this earthquake is applied on the bare frame (without masonry infill walls), then the "Significant Damage" limit state is satisfied having some damages. If the same earthquake is applied on the infilled frame, then the building does not enter the nonlinear region, so no damage is expected on the frame members.

For the seismic hazard zone I of the Greece, an earthquake that has a mean return period of 2475 years has been considered as the Maximum Capable Earthquake (MCE). This earthquake has been taken as twice as large as the DBE. If this earthquake is applied on the bare frame, then the building fails. The maximum earthquake where the bare building can take without collapse (ultimate earthquake) has been estimated at $1.30 \cdot \mathrm{DBE}$. However, if the MCE is applied on the infill building, then the building suffers limited damage, similar to that corresponding to the yielding state of the building, Fig. (14). This fact indicates that the role of 
wedged masonry infill walls is very important, since significant additional strength has been given to building.

Lastly, in order to investigate the "Damage Limitation" level, as Frequent Earthquake has been used that with $0.60 \cdot \mathrm{DBE}$. Also, the effective flexural stiffness has been set to $50 \%$ of that corresponding to the geometric cross-sections (sect.4.3.1(7)/EN 1998-1). Moreover, for each masonry infill wall, two diagonal bars have been used, where each one has axial-stiffness $E A_{\mathrm{eff}}=0.50 E_{\mathrm{E}} A_{\mathrm{W}}$. The result of these analyses, show that the storey drifts remain at low level, $\gamma \leq 0.005$ for the brittle masonry infill walls according to sect.4.4.3.2(1)a of EN 1998-1 (considered equivalent factor $v=0.60$ ). Also, in order to measure the structural damage realistically and reliably, an advanced work can be taken place calculating the Park-Ang damage index of each damage-level of the building [30-32] since, firstly, an optimum equivalent non-linear single degree of freedom system of the irregular in-plan asymmetric multi-storey building has been defined [5-7]. Moreover, a very remarkable and advanced work about various issues of the energy dissipated by inelastic structures has been published recently [33].

\section{CONCLUSIONS}

In the present paper, the validity of the seismic performance matrix of Eurocode EN 1998-3 is checked numerically, using a group of irregular in-plan, torsionally-flexible multistorey r/c buildings with and without masonry infill walls. For the non-linear response-history analyses, seven pairs of suitable artificial accelerograms that have been developed for the needs of the present article have been used. Moreover, the static pushover analysis has been used also, according to EN 1998. For illustrative purposes, a torsionally-flexible three-storey r/c building designed according to EN 1998-1 for Ductility Class High, using building behavior factor $q=3.00$ is presented as a case-study. The following conclusions arise from the non-linear seismic analyses:

a. For the Frequent Earthquake (0.60 DBE), the target of "Damage Limitation" is satisfied fully, since no damage of the masonry infill walls occurs.

b. For the Design Basis Earthquake (DBE) the target of "Significant Damage" is satisfied fully, but it is true thanks to masonry infill walls exclusively. In the case when the masonry infill walls are ignored then the target is not satisfied and the building collapses.

c. For the Maximum Capable Earthquake, (2.00-DBE), when all wedged masonry infill walls have been taken into account, the target of "Near Collapse" is satisfied fully. If the masonry infill walls are ignored, as it happen according to KANEPE 2012, then the building collapses. The ultimate earthquake is estimated at $1.30 \cdot \mathrm{DBE}$.

d. On the one hand, the overstrength of the building for static lateral floor loading along I-axis approaches a factor five with reference to seismic design level, which is defined as the earthquake level divided by behavior factor $q=3.00$, but, on the other hand, the available ductility of the building is restricted, since it ranges around 2.20 (Figs. 12, 13). It is worth noting that the r/c walls are nearly orientated along I-axis and the multi-storey building is irregular in-plan because it is torsionaly-flexible.

e. Shear failure precedes flexural failure in $15 \%$ of the vertical stiffness members (columns C5 \& C6), despite the fact that all provisions of Eurocode EN 1998-1 have been applied for the Ductility Class High. Moreover, shear failure precedes flexural failure at $40 \%$ of the beams. These percentages of shear failure are very high. In order to avoid such state, special care (repeated re-design is required) must be taken into account. In other words, in each case of a newly designed r/c building, the use of part 3 of EN 1998 has to be applied always for the daily design seismic procedure. This is the most important conclusion of the present paper. The small available ductility of the building, along I \& II-axes, due to the high shear failures that took place.

f. The role of reduced flexural stiffness (about 50\% according to sect.4.3.1(7) of Eurocode EN 1998-1) of r/c member sections leads to higher fundamental period of the building (without masonry infill walls) from $0.63 \mathrm{~s}$ to 0.89 s. Thus, according to elastic acceleration spectrum for soil category D of Eurocode EN 1998-1, the building model and the design earthquake are co-ordinated (namely the fundamental eigen-period of the building is very close to predominant period of the earthquake, in other words the first eigen period of the building is located into the plateau of the design acceleration spectrum).

g. The role of more reduced flexural stiffness (such as it arises by Eq. (9)) of r/c member sections leads to very large fundamental periods of the building (without masonry infill walls) from $0.89 \mathrm{~s}$ to $1.71 \mathrm{~s}$. Thus, the fundamental eigen-period of the building is transformed artificially, in an area where the co-ordination between building and earthquake cannot exist. Therefore, in this case, the building is loaded inadequately seismically (i.e. for Maximum Capable Earthquake). However, this disadvantage is removed for the Design Basis Earthquake, if masonry infill walls inserting to building's model, since then the fundamental eigen-period is $0.48 \mathrm{~s}$.

\section{CONFLICT OF INTEREST}

The authors confirm that this article content has no conflicts of interest.

\section{ACKNOWLEDGEMENT}

None declared.

\section{REFERENCES}

[1] EN 1992-1-1., (2004). Eurocode 2: Design of concrete structures part 1-1: General rules and rules for buildings. European Committee for Standardization, Brussels.

[2] EN 1998-1., (2004). Eurocode 8: Design of structures for earthquake resistance - Part 1: General rules, seismic actions and rules for buildings. European Committee for Standardization, Brussels.

[3] EN 1998-3., (2005). Eurocode 8: Design of structures for earthquake resistance - Part 3: Assessment and retrofitting of building. European Committee for Standardization, Brussels.

[4] A. Arias, "A measure of earthquake intensity", In: R.J. Hansen, Ed. Seismic Design for Nuclear Power Plants, Massachusetts, MIT Press: Cambridge, 1970, pp. 438-483.

[5] T. Makarios, "Equivalent Non-Linear SDF system of spatial asymmetric multistory buildings in pushover procedure. Theory \& 
Applications", Struct. Des. Tall. Special Buildings, vol. 18, no. 7, pp.729-763, 2009.

[6] T. Makarios, "The equivalent non-linear single degree of freedom system of asymmetric multi-storey buildings in seismic static pushover analysis", In: "Earthquake Research and Analysis / Book 4. Book edited by Prof. Abbas Moustafa. INTECH, Open Access Publisher, ISBN 979-953-307-680-4, 2011. (in press).

[7] T. Makarios, "Seismic non-linear static new method of spatial asymmetric multi-storey r/c buildings", Struct. Des. Tall. Special Buildings, 2012. DOI: 10.1002/tal.640 (in press).

[8] H. Banon, J.M. Biggs, and H.M. Irvine, "Seismic damage in reinforced concrete frames", J. Struct. Eng. ASCE, vol. 107, no. 9, pp. 1713-1729, 1981.

[9] KANEPE, Approval of Hellenic Code of Retrofitting of Reinforced Concrete Buildings. Organization of Seismic Design \& Protection (OASP). FEK 42/b/January 20, 2012. Hellenic Ministry of Infrastructure, Transport and Network, 2012. (in Greek).

[10] XTRACT. v.3.0.8., Cross-sectional X structural Analysis of Components. Imbsen Software System. 9912 Business Park Drive, Suite 130, Sacramento CA 95827, 2007.

[11] T. Panagiotakos, and M. Fardis, "Estimation of inelastic deformation demands in multistory rc buildings", J. Earthquake Eng. Struct. Dyn., vol. 28, pp. 501-528, 1999.

[12] T. Panagiotakos, and M. Fardis, "Deformations of reinforced concrete members at yielding and ultimate", ACI Struct. J., vol. 98, no. 2, pp. 135-148, 2001.

[13] R.J. Mainstone, and G.A. Weeks, The influence of Bounding Frame on the Racking Stiffness and Strength of Brick Walls, Proceedings of the 2nd International Brick Masonry Conference, Building Research Establishment, Watford, England, 1970, pp. $165-171$.

[14] R.J. Mainstone, Supplementary note on the stiffness and strengths of infilled frames, Current Paper CP 13/74, Building Research Station, Garston, Watford, U.K, 1974.

[15] Federal Emergency Management Agency, "NEHRP Commentary on the Guidelines for the Seismic Rehabilitation of Buildings." FEMA-274, Applied Technology Council, Washington, DC, 1997.

[16] Federal Emergency Management Agency, "Evaluation of earthquake damaged concrete and masonry wall buildings: basic procedures manual." FEMA-306, Applied Technology Council, Washington, DC, 1998.

[17] P.G. Asteris, "Lateral stiffness of brick masonry infilled plane frames", J. Struct. Eng., ASCE, vol. 129, no. 8, pp. 1071-1079, 2003.

[18] P.G. Asteris, Closure to "Lateral Stiffness of Brick Masonry Infilled Plane Frames", J. Struct. Eng., ASCE, vol. 131, no. 3, pp. 523-524, 2005.

[19] P.G. Asteris, "Finite Element Micro-Modelling of Infilled Frames", Electron. J. Struct. Eng., vol. 8, pp. 1-11, 2008.
[20] P.G. Asteris, C. Chrysostomou, I. Giannopoulos, and E. Smyrou, "Masonry infilled reinforced concrete frames with openings", Proc. $3 r d$ International Conference on Computational Methods in Structural Dynamics and Earthquake Engineering (COMPDYN 2011), 26-28 May, 2011, Corfu, Greece.

[21] P.G. Asteris, S.T. Antoniou, D.S. Sophianopoulos, and C.Z. Chrysostomou, "Mathematical macromodeling of infilled frames: state of the art", J. Struct. Eng., (ASCE), vol. 137, no. 12, pp. 15081517, 2011.

[22] P.G. Asteris, D.J. Kakaletsis, C.Z. Chrysostomou, and E.E. Smyrou, "Failure modes of infilled frames", Electron. J. Struct. Eng., vol. 11, no. 1, pp. 11-20, 2011.

[23] P.G. Asteris, I. Giannopoulos, and C. Chrysostomou, "Modeling of infilled frames with openings", Open Constr. Build. Technol. J., vol. 6, pp. 81-91, 2012.

[24] T. Makarios, and K. Anastassiadis, "Real and fictitious elastic axis of multi-storey buildings: theory", Struct. Des. Tall. Special Buildings, vol. 7, no. 1, pp. 33-55, 1998a.

[25] T. Makarios, and K. Anastassiadis, "Real and fictitious elastic axis of multi-storey buildings: application", Struct. Des. Tall. Special Buildings, vol. 7, no. 1, pp. 57-71, 1998b.

[26] T. Makarios, A. Athanatopoulou, and H. Xenidis, "Numerical verification of properties of the fictitious elastic axis in asymmetric multistorey buildings", Struct. Des. Tall. Special Buildings, vol. 15, no. 3, pp. 249-276, 2006.

[27] T. Makarios, "Practical calculation of the torsional stiffness radius of multistorey tall buildings", Struct. Des. Tall. Special Buildings, vol. 17, no. 1, pp. 39-65, 2008.

[28] N. Theodoulidis, I. Kalogeras, C. Papazachos, V. Karastathis, B. Margaris, C. Papaioannou, and A.A. Skarlatoudis, "A. HEAD 1.0: A unified hellenic accelerogram database", Seismol. Res. Lett., vol. 75, no. 1, pp. 36-45, 2004.

[29] H. Hilber, T. Hughes, and R. Taylor, "Improved numerical dissipation for the time integration algorithms in structural dynamics", Earthquake Eng. Struct. Dyn. J., vol. 5, pp. 283-292, 1997.

[30] Y-J. Park, and A. H-S. Ang, "Mechanistic seismic damage model for reinforced concrete", J. Struct. Eng. ASCE, vol. 111, no. 4, pp. 722-739, 1985 .

[31] S. Ghosh, D. Datta, and A.A. Katakdhond, "Estimation of ParkAng damage index in planar multi-storey frames using equivalent single-degree systems", Eng. Struct., vol. 33, no. 9, pp. 2509-2524, 2011.

[32] A. Moustafa, "Damage-based design earthquake loads for SDOF inelastic structures", J. Struct. Eng., vol. 137, no. 3, pp. 456-467, 2011.

[33] A. Moustafa, "Critical earthquake load inputs for multi-degree-offreedom inelastic structures", J. Sound Vib., vol. 325, pp. 532-544, 2009.

(C) Makarios and Asteris; Licensee Bentham Open.

This is an open access article licensed under the terms of the Creative Commons Attribution Non-Commercial License (http://creativecommons.org/licenses/by-nc/3.0/) which permits unrestricted, non-commercial use, distribution and reproduction in any medium, provided the work is properly cited. 